\title{
Research on Compound Pitch Control Technology of Direct-drive Perma- nent Magnet Wind Turbine
}

\author{
Yancai Xiao*, Wenjian Huo and Guiqing Nan
}

School of Mechanical, Electronic and Control Engineering, Beijing Jiaotong University, Beijing, China

\begin{abstract}
The conventional PID pitch controller was usually used in direct-drive permanent magnet wind turbine in order to maintain the output power unchanged above the rated wind speed. However, due to the complex structure of wind turbine as well as high nonlinearity of wind speed, the effect of PID control method is often less than ideal. A new pitch control method combined with fuzzy adaptive PID and fuzzy feed forward controller is proposed in this paper. The fuzzy adaptive PID controller is able to ensure the unit having a better control result than PID controller at various wind speeds. The fuzzy feed forward controller has improved the responsiveness of pitch control system. With the simulation of a $1.5 \mathrm{MW}$ wind turbine, the responsiveness and stability of wind turbine can be effectively proved by the new pitch control method above the rated wind speed, the system's overshoot is also reduced, which satisfies the demand of power control.
\end{abstract}

Keywords: Fuzzy adaptive PID controller, fuzzy feed forward controller, variable pitch, wind turbines.

\section{INTRODUCTION}

At present, the pitch control method is usually adopted above the rated wind speed by large wind turbines. The aerodynamic torque of wind turbine is changed by adjusting the pitch angle to achieve constant power. The PID controller is mostly used to achieve the pitch control in wind turbines. However, due to the randomness of the wind speed variations and the strong nonlinearity of the wind turbines, PID control cannot achieve satisfactory results. In recent years, many researchers try to design pitch controllers by using intelligent methods, such as reference [1], variable universe adaptive fuzzy control strategy is used to control the pitch angle above the rated power, which effectively reduces the fluctuation effect of high frequency component of wind speed data on power regulation. It shows that the system has good dynamic performance. In reference [2], the control strategy combining predictive control based on neural networks with feed-forward control is presented, which realized the control of the wind turbine, but it is difficult to establish the optimal reference model. In reference [3], the compound pitch control strategy combining fuzzy feed-forward controller with fuzzy PID controller is presented. The fuzzy PID controller used the switching rule of the fuzzy controller and the PID controller in different working condition. Although to some extent, the controller improved the control effect, but the PID control parameters could not be properly adjusted with the working conditions. So when the wind speed changes, its control effect may be worse. Based on the above studies, the new compound pitch controller combining fuzzy adaptive PID controller with fuzzy feed-forward controller is proposed. The PID control parameters are adaptive adjusted according to the system error and the rate of error changes by the fuzzy rules. Using fuzzy feed-forward control changes the influence of inertial and delay of pitch-regulated system on dynamic performance. Above rated wind speed, the input pitch angle of wind turbine is gotten by combining the different output values of the fuzzy adaptive PID controller and the feed-forward controller. The simulation results show that the new method can effectively ensure the rapid response and stability of wind turbine, reduce the overshoot of system, and the effect of the control is better.

\section{MODELING OF WIND TURBINES} [4].

The modeling of wind turbines consists of four sections

\subsection{Wind Turbine Model}

Let $\mathrm{P}$ be the mechanical power of wind turbine and let $T_{m}$ be the input torque, then the relation between the two and wind speed $v$ is:

$$
\begin{aligned}
& P=\frac{1}{2} C_{p}(\beta, \lambda) \rho \pi R^{2} v^{3} \\
& T_{m}=\frac{1}{2} C_{p}(\beta, \lambda) \rho \pi R^{3} v^{2} / \lambda
\end{aligned}
$$

where $\mathrm{P}$ is output power $(\mathrm{W}) ; T_{m}$ is torque of wind turbine $(\mathrm{Nm}) ; \rho$ is air density $\left(\mathrm{kg} / \mathrm{m}^{3}\right) ; C_{D}$ is wind power coefficient; $\beta$ is pitch angle (deg); $\lambda$ is blade top speed ratio; $\mathrm{R}$ is blade radius of wind turbine $(\mathrm{m})$. 
Wind power coefficient $C_{p}$ represents the wind turbine's capacity of absorbing power from wind, the functional relation among wind power coefficient $C_{p}$ and blade top speed ratio $\lambda$ and pitch angle $\beta$ is expressed as follows [5]:

$$
\left\{\begin{array}{l}
C_{p}(\lambda, \beta)=0.22\left(\frac{116}{\lambda_{i}}-0.4 \beta-5\right) e^{-\frac{12.5}{\lambda_{i}}} \\
\frac{1}{\lambda_{i}}=\frac{1}{\lambda+0.08 \beta}-\frac{0.035}{\beta^{3}+1}
\end{array}\right.
$$

\subsection{Transmission System Model}

Due to the gearbox of direct-drive permanent magnet wind turbine is subtracted, the motion equation is [6]:

$J_{r} \frac{d \omega}{d t}=T_{r}-T_{m}$

where $J_{r}$ is rotational inertia of wind turbine; $\omega$ is rotational speed of wind turbine; $T_{r}$ is the aerodynamic torque of wind turbine; $T_{m}$ is the torque that transmission delivers to generator.

\subsection{Permanent Magnet Generator Model}

The mathematical model of permanent magnet synchronous generator that this paper established in the $d q$ synchronous rotating reference orthogonal coordinate system is [7]:

$$
\left\{\begin{array}{l}
\frac{d i_{d}}{d t}=-\frac{R_{a}}{L_{d}} i_{d}+\omega_{e} \frac{L_{q}}{L_{d}} i_{q}+\frac{1}{L_{d}} u_{d} \\
\frac{d i_{q}}{d t}=-\frac{R_{a}}{L_{q}} i_{q}-\omega_{e}\left(\frac{L_{d}}{L_{q}} i_{d}+\frac{1}{L_{q}} \lambda_{0}\right)+\frac{1}{L_{q}} u_{q}
\end{array}\right.
$$

where $i_{d}$ and $i_{q}$ are current of $d$ axis and $q$ axis of generator respectively; $L_{d}$ and $L_{q}$ are inductance of $d$ axis and $q$ axis of generator respectively; $R_{a}$ is stator resistance; $\omega_{e}$ is electrical angular frequency, $\omega_{e}=n_{p} \omega_{g} ; n_{p}$ is number of pole pairs of generator rotor; $\lambda_{0}$ is flux of permanent magnet; $u_{d}$ and $u_{a}$ are $d$ axis component and $q$ axis component of $u_{g}$. Define back emf of $q$ axis $e_{a}=\omega_{e} \lambda_{0}$, back emf of $d$ axis $e_{d}=0$. Assume the inductance of $d$ axis and $q$ axis of generator are equal, that $L_{d}=L_{q}=L$, then formula (5) can be written as:

$$
\left\{\begin{array}{l}
\frac{d i_{d}}{d t}=-\frac{R_{a}}{L} i_{d}+\omega_{e} i_{q}+\frac{1}{L_{d}} u_{d} \\
\frac{d i_{q}}{d t}=-\frac{R_{a}}{L} i_{q}-\omega_{e}\left(i_{d}+\frac{1}{L} \lambda_{0}\right)+\frac{1}{L} u_{q}
\end{array}\right.
$$

\subsection{Pitch Control Actuator Model}

At present, the actuator of large wind turbine mostly adopts hydraulic drive system. The system equation of reference pitch angle and actual pitch angle is [8]:

$$
\frac{d \beta}{d t}=\frac{1}{T_{\beta}}\left(\beta_{r}-\beta\right)
$$

Considering the delayed hydraulic system, pitch control actuator can be replaced by a one order inertial link with time delay, the transfer function is:
$\frac{\beta(s)}{\beta_{r}(s)}=\frac{1}{T_{\beta} s+1} e^{-\tau s}$

where $T_{B}$ is time constant; $\beta_{r}$ is reference pitch angle; $\tau$ is delay time.

\section{DESIGN OF PITCH CONTROL SYSTEM}

Power feedback control is adopted by the pitch control system to maintain constant power. The given value of control signal is constant here, namely rated power. In order to decrease the wind power that wind turbine absorbed and ensure the generator is working under the rated power, the pitch angle is increased when actual power exceeds the rated power; conversely, the pitch angle is decreased to increase the power that wind wheel absorbed. The wind turbine generator was kept to work under the rated power through pitch control.

The wind turbine is a complex system which has the qualities of nonlinearity, multi-variable and time variation, so that traditional PID control can hardly accomplish the control target with high performance. A group of PID parameters which have been already set may have a good control effect while the wind speed is near the rate speed, however, the control effect would become poor, if the wind speed increased to the vicinity of cut-out wind speed $[9,10]$. And for the pitch system, there is a certain inertia and delay, so inevitably result in a large overshoot and a longer adjusting time, the output power fluctuation is too large, resulting in a greater impact to the grid. According to the above disadvantages of conventional methods of pitch control, considering also that the fuzzy control can be efficiently integrated the experience and knowledge of experts, has a good dynamic performance and robustness, the new compound pitch controller combining fuzzy adaptive PID controller with fuzzy feed-forward controller is proposed in this paper. Structure of the pitch control system is shown in Fig. (1).

\subsection{Design of Fuzzy Adaptive PID Controller}

Fuzzy adaptive PID control is a process that calculating the current systematic error $e$, rate of error $e_{c}$, studying on the fuzzy reasoning with fuzzy rules, then adjusting the PID parameters based on the fuzzy matrix table [11]. Fuzzy adaptive PID controller has two input variables, namely power error and rate of error. Its output variables are parameter increments of PID controller $\Delta K_{p}, \Delta K_{i}, \Delta K_{d}$.

In this paper, the rated power of wind turbine generator is $1.5 \mathrm{MW}$. Assign the basic universe of power error as [-1.5, $1.5]$ and the basic universe of rate of error as $[-6,6]$.

After we determined the reasonable quantization factor and scale factor of input variables and output variables, fuzzy universe of controller's input and output values are all equal to:

$\left\{\begin{array}{c}e, e c=\{-6,-4,-2,0,2,4,6\} \\ \Delta K_{p}=\{-6,-4,-2,0,2,4,6\} \\ \Delta K_{i}=\{-0.3,-0.2,-0.1,0,0.1,0.2,0.3\} \\ \Delta K_{d}=\{-0.06,-0.04,-0.02,0,0.02,0.04,0.06\}\end{array}\right.$ 


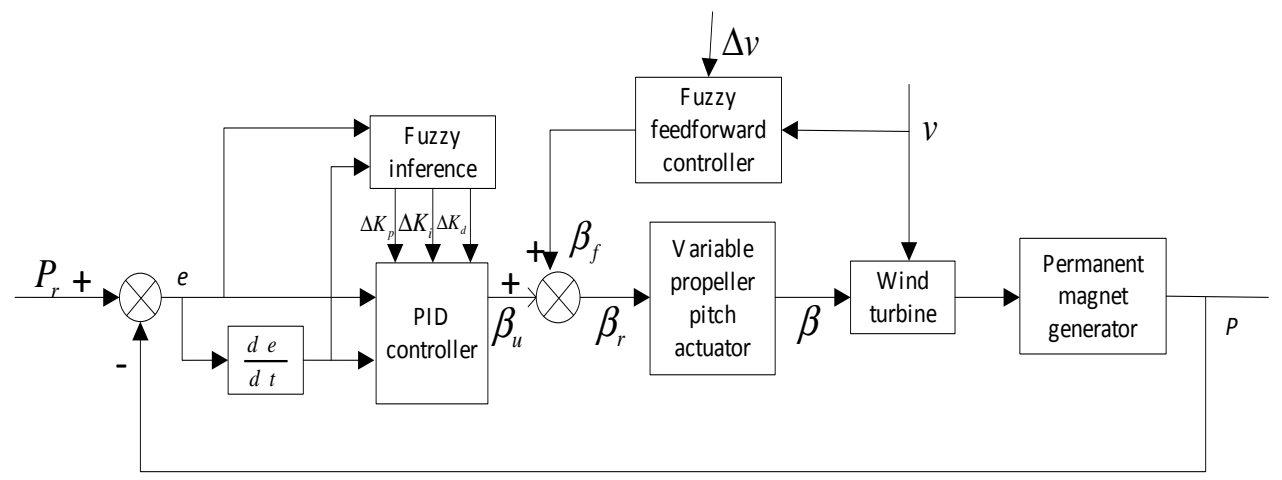

Fig. (1). Structure of the pitch control system.

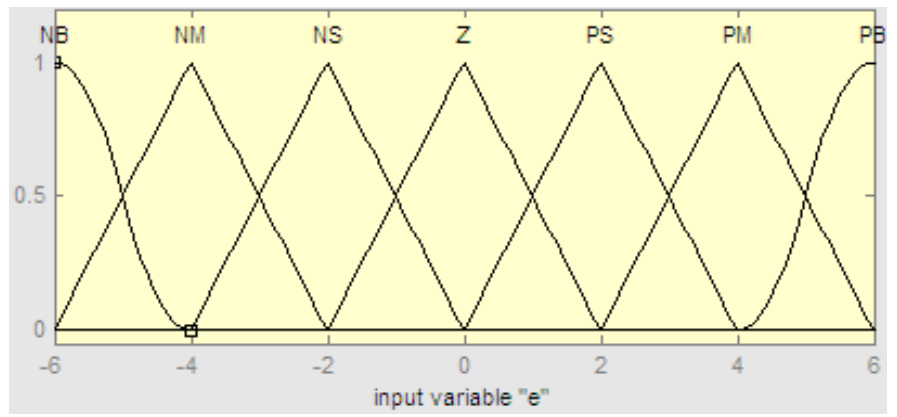

Fig. (2). Membership function of error $e$.

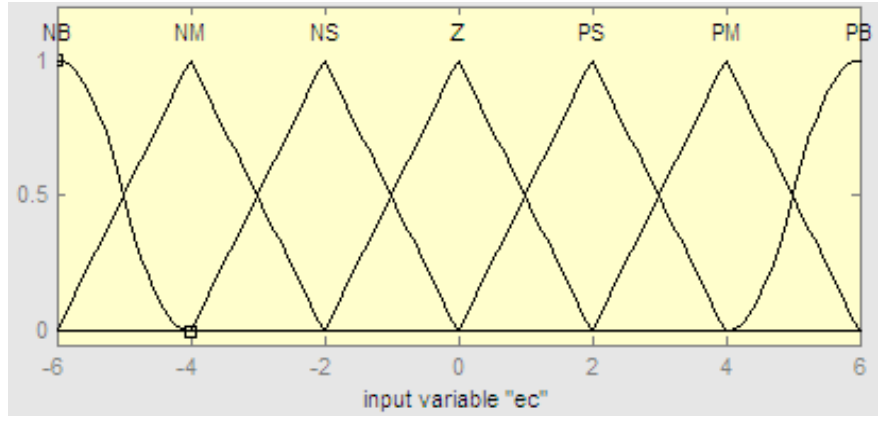

Fig. (3). Membership function of $e_{c .}$.

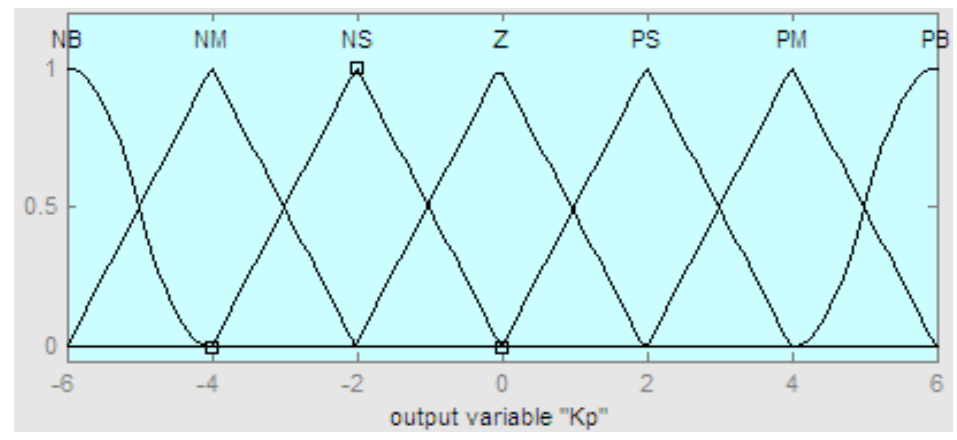

Fig. (4). Membership function of $\Delta K_{p}$.

Assign the fuzzy subset as: $\{\mathrm{NB}, \mathrm{NM}, \mathrm{NS}, \mathrm{Z}, \mathrm{PS}, \mathrm{PM}$, PB $\}$. The Fig. (2) shows the membership function of error $e$. Then the membership functions of $e_{c}, \Delta K_{p}, \Delta K_{i}, \Delta K_{d}$ can be expressed in a similar way. They are shown in Fig. (3), Fig. (4), Fig. (5), Fig. (6) respectively.

Determine the fuzzy control rules of power according to the requirements of power adjustment. The rule base is com- posed of a series of fuzzy conditional statements like "if E and EC then U", they are shown in Table 1, $\mathbf{2}$ and $\mathbf{3}$ below.

\subsection{Design of Fuzzy Feed-Forward Controller}

The objective of pitch control system is to ensure that output power is constant at any time when the wind speed is 


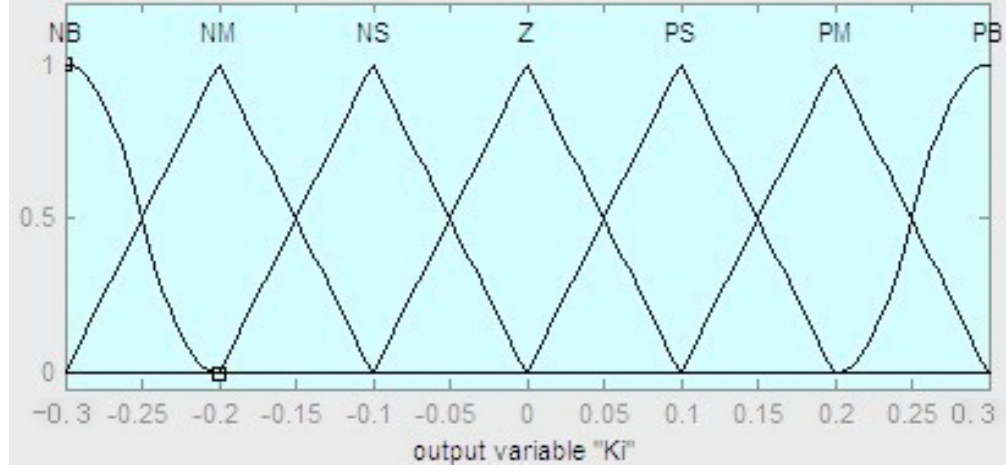

Fig. (5). Membership function of $\Delta K_{i}$.

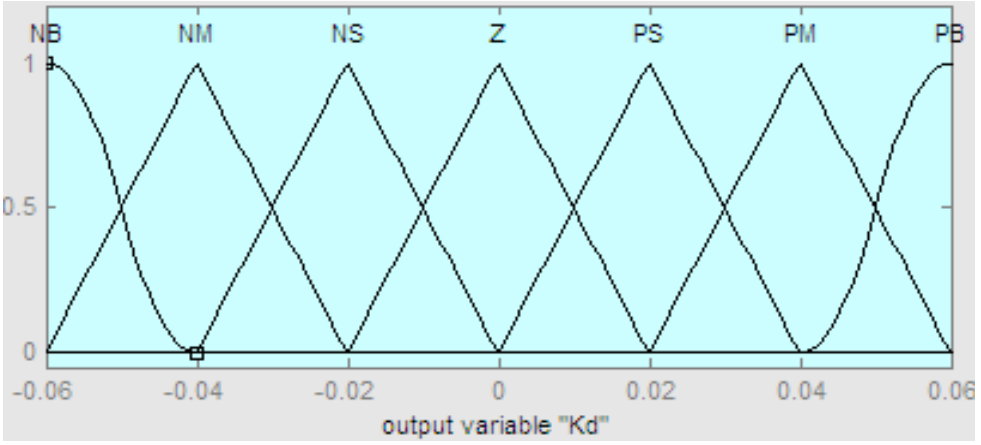

Fig. (6). Membership function of $\Delta K_{d}$.

changing. In Fig. (1), the effect of fuzzy feed-forward controller is providing the reasonable feed-forward value of pitch angle $\beta_{f}$, then plus it with the output value of fuzzy PID controller $\beta_{u}$. The result is the set value $\beta_{r}$ of the pitch control system. When the wind speed increases, the output value of fuzzy feed-forward controller is positive. Increase the setting value of pitch angle timely and reduce the wind power that wind wheel absorbed. Conversely, the output value of fuzzy feed-forward controller is negative, then increase the power that wind wheel absorbed to keep the power constant above the rated wind speed. The rapid compensation of feedforward controller can efficiently overcome the disadvantage of accommodative lag that PID controller has $[12,13]$.

Table 1. Fuzzy control rules of $\Delta K_{p}$.

\begin{tabular}{|c|c|c|c|c|c|c|c|}
\hline \multirow{2}{*}{$\boldsymbol{e}$} & \multicolumn{7}{|c|}{$\boldsymbol{e}_{\boldsymbol{c}}$} \\
\cline { 2 - 8 } & NB & NM & NS & $\mathbf{Z}$ & PS & PM & PB \\
\hline \hline NB & NB & NB & NM & NM & NS & Z & Z \\
\hline NM & NB & NB & NM & NS & NS & Z & NS \\
\hline NS & NM & NM & NM & NS & Z & PS & PS \\
\hline Z & NM & NM & NS & Z & PS & PM & PM \\
\hline PS & PS & PS & PS & PM & PM & PB & PB \\
\hline PM & PS & PS & PM & PB & PB & PB & PB \\
\hline PB & PS & PS & PM & PB & PB & PB & PB \\
\hline
\end{tabular}

Table 2. Fuzzy control rules of $\Delta K_{i}$.

\begin{tabular}{|c|c|c|c|c|c|c|c|}
\hline \multirow{2}{*}{$\boldsymbol{e}$} & \multicolumn{7}{|c|}{$\boldsymbol{e}_{\boldsymbol{c}}$} \\
\cline { 2 - 8 } & NB & NM & NS & $\mathbf{Z}$ & PS & PM & PB \\
\hline \hline NB & NB & NB & NM & NM & NS & Z & Z \\
\hline NM & NB & NS & NM & NS & NS & Z & Z \\
\hline NS & NB & NM & NS & NS & Z & PS & PS \\
\hline Z & NM & NM & NS & Z & PS & PM & PM \\
\hline PS & NS & Z & PS & PM & PM & PB & PB \\
\hline PM & PS & PS & PM & PM & PB & PB & PB \\
\hline PB & PS & PS & PM & PB & PB & PB & PB \\
\hline
\end{tabular}

Table 3. Fuzzy control rules of $\Delta K_{d}$.

\begin{tabular}{|c|c|c|c|c|c|c|c|}
\hline \multirow{2}{*}{$\boldsymbol{e}$} & \multicolumn{7}{|c|}{$\boldsymbol{e}_{\boldsymbol{c}}$} \\
\cline { 2 - 8 } & NB & NM & NS & $\mathbf{Z}$ & PS & PM & PB \\
\hline \hline NB & PS & NS & NB & NB & NB & NM & PS \\
\hline NM & PS & NS & NB & NM & NM & NS & Z \\
\hline NS & Z & NS & NM & NM & NS & NS & Z \\
\hline Z & Z & NS & NS & NS & NS & NS & Z \\
\hline PS & Z & Z & Z & Z & Z & Z & Z \\
\hline PM & PB & NS & PS & PS & PS & PS & PB \\
\hline PB & PB & PM & PM & PM & PS & PS & PB \\
\hline
\end{tabular}




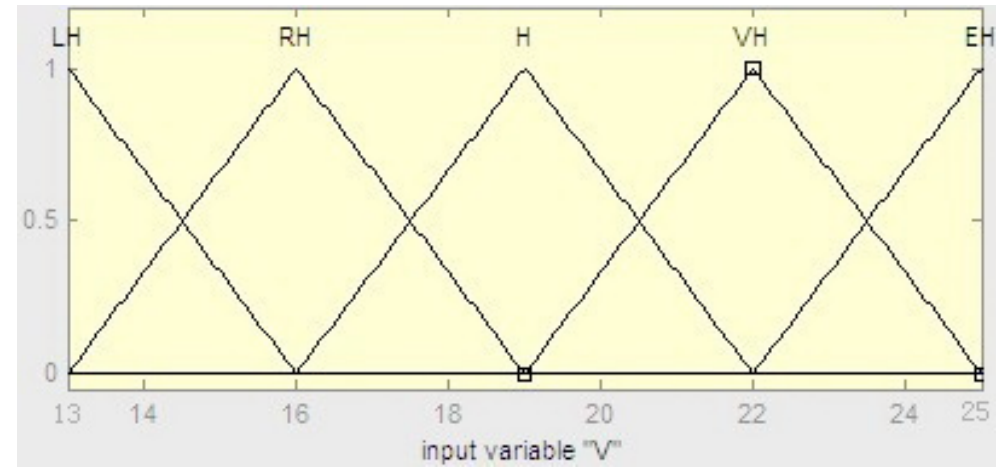

Fig. (7). Membership function of wind speed.

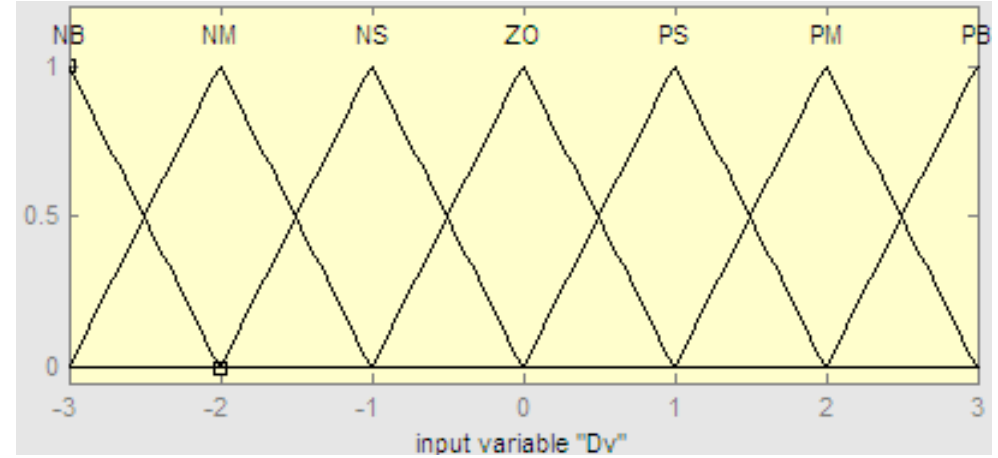

Fig. (8). Membership function of wind speed variation.

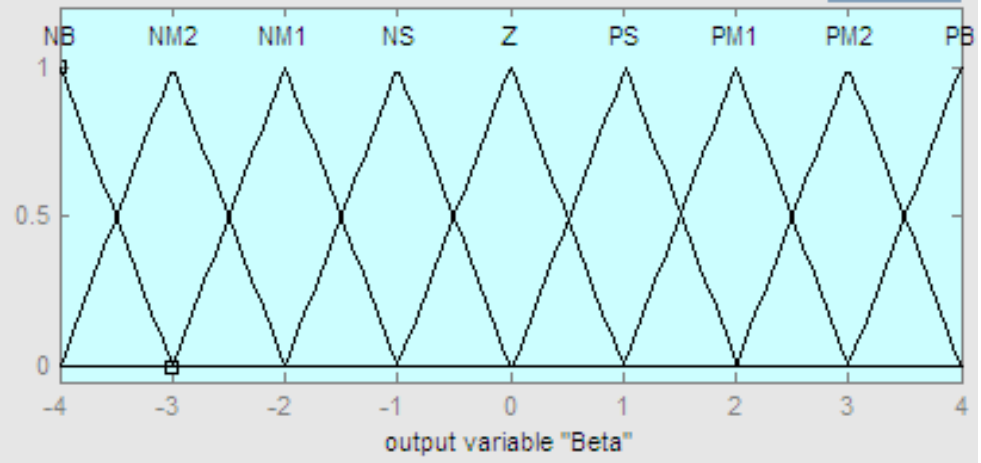

Fig. (9). Membership function of feed forward pitch.

Fuzzy feed-forward controller has two input variables. One is wind speed last moment $v(k-1)$, the other is the difference between wind speed this moment and last moment $\Delta v=v(k)-v(k-1)$. The output variable is the feed-forward pitch angle $\beta_{f}$. When the same wind speed change $\Delta v$ is happening, the fuzzy feed-forward controller would output a bigger $\beta_{f}$ if the value of $v(k-1)$ is near the rated wind speed; conversely, the controller would output a smaller $\beta \mathrm{f}$ if the value of $v(k-1)$ is near the cut-out wind speed.

The rated wind speed of wind turbine is $13 \mathrm{~m} / \mathrm{s}$ and the cut-out wind speed is $25 \mathrm{~m} / \mathrm{s}$ in the research of this paper. For fuzzy feed-forward controller, the basic universe of input variable $v(k-1)$ is $[13 \mathrm{~m} / \mathrm{s}, 25 \mathrm{~m} / \mathrm{s}]$. Assign the fuzzy universe is $\{13,16,19,22,25\}$, respectively corresponding to the fuzzy subset: little high, relatively high, high, very high, ex- tremely high, which being abbreviated as $\{\mathrm{LH}, \mathrm{RH}, \mathrm{H}, \mathrm{VH}$, $\mathrm{EH}\}$.

The basic universe of input variable $\Delta v$, is $[-3 \mathrm{~m} / \mathrm{s}, 3 \mathrm{~m} / \mathrm{s}]$, corresponding to the fuzzy universe $\{-3,-2,-1,0,1,2,3\}$ and the fuzzy subset is $\{\mathrm{NB}, \mathrm{NM}, \mathrm{NS}, \mathrm{Z}, \mathrm{PS}, \mathrm{PM}, \mathrm{PB}\}$.

The basic universe of output variable $\beta \mathrm{f}$ is $\left[-4^{\circ}, 4^{\circ}\right]$. Assign the fuzzy universe is $[-4,4]$ and the fuzzy subset is $\{\mathrm{NB}$, NM2, NM1, NS,Z, PS, PM1, PM2, PB \}.

The membership functions of fuzzy feed-forward controller all adopt triangular membership function as shown in Fig. (7), Fig. (8) and Fig. (9). Defuzzification method is gravity method. According to the research above, we get the relation between feed-forward pitch angle and different wind speed, then we get the concrete fuzzy rules as shown in Table 4. 


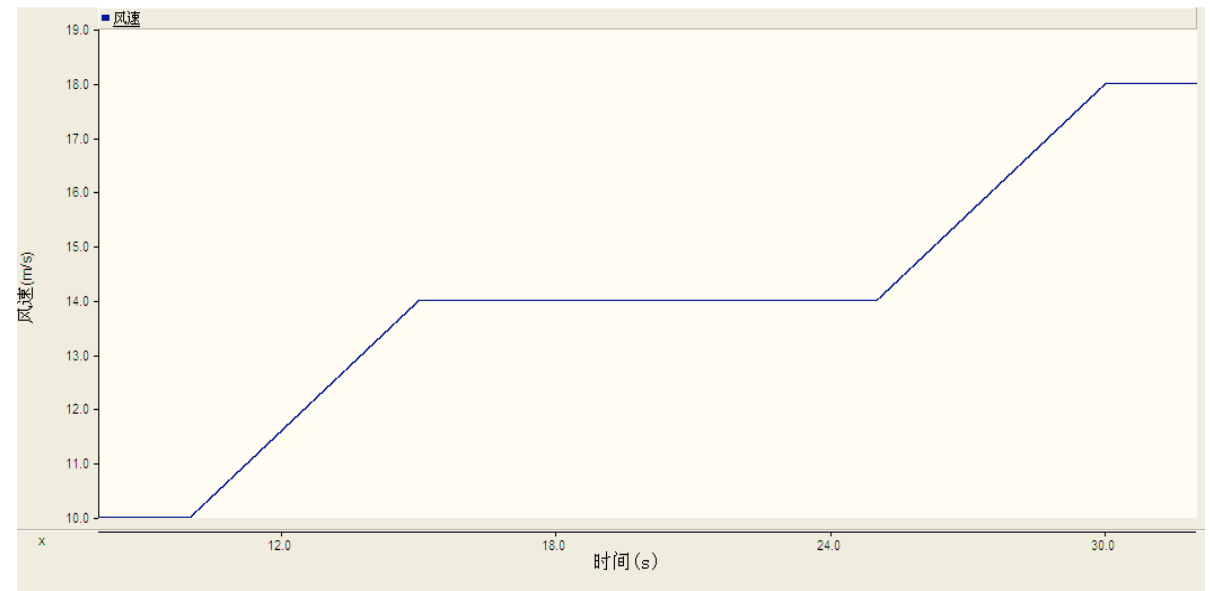

Fig. (10). Wind speed profile.

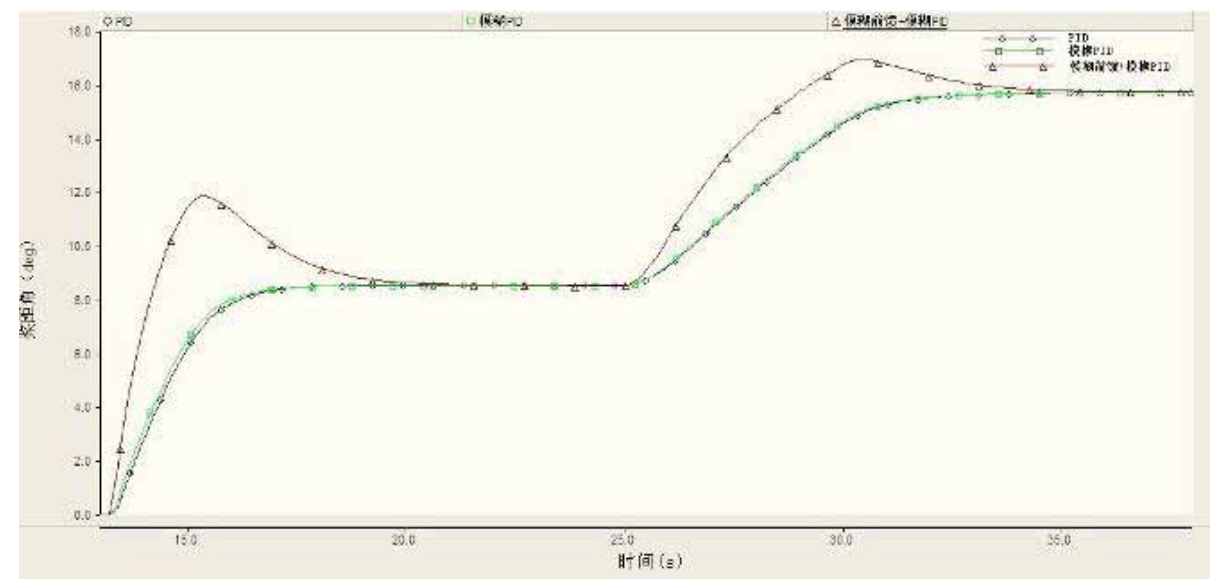

Fig. (11). Pitch response near the rated wind speed.

Table 4. Rules of fuzzy feed forward controller.

\begin{tabular}{|c|c|c|c|c|c|}
\hline \multirow{2}{*}{$\Delta \boldsymbol{v}$} & \multicolumn{5}{|c|}{$v$} \\
\cline { 2 - 6 } & $\mathbf{L H}$ & $\mathbf{R H}$ & $\mathbf{H}$ & $\mathbf{V H}$ & $\mathbf{E H}$ \\
\hline \hline NB & NB & NB & NM2 & NM1 & NS \\
\hline NM & NB & NM2 & NM1 & NS & NS \\
\hline NS & NM1 & NS & NS & NS & NS \\
\hline Z & Z & Z & Z & Z & Z \\
\hline PS & PM1 & PM1 & PS & PS & PS \\
\hline PM & PB & PM2 & PM1 & PS & PS \\
\hline PB & PB & PB & PM2 & PM1 & PS \\
\hline
\end{tabular}

\section{SIMULATION}

The parameters of wind turbine in the simulation of this paper are: radius of wind wheel $R=38.5 \mathrm{~m}$, rated wind speed $v_{e}=13 \mathrm{~m} / \mathrm{s}$, cut-out wind speed $v_{\text {out }}=25 \mathrm{~m} / \mathrm{s}$, air density $\rho=1.225 \mathrm{~kg} / \mathrm{m}^{3}$; time constant of pitch control system $T_{\beta}=0.2$, delay time $\tau=0.3 \mathrm{~s}$. Equivalent rotational inertia of the wind turbine $J_{e q}=6.12 \times 10^{5} \mathrm{~kg} \bullet \mathrm{m}^{2}$, rated power of wind turbine is $1.5 \mathrm{MW}$, number of role pairs of motor $\mathrm{g}=39$, inductance $L_{d}=L_{q}=1.7 \mathrm{mH}$, flux linkage of permanent magnet $\lambda_{0}=0.1167 \mathrm{~Wb}$, transmission viscosity coefficient $B_{m}=0$;

(1) In the vicinity of rated wind speed. According to the Fig. (10), from $11 \mathrm{~s}$ to $15 \mathrm{~s}$, wind speed gradually increased from $10 \mathrm{~m} / \mathrm{s}$ to $14 \mathrm{~m} / \mathrm{s}$; from $26 \mathrm{~s}$ to $30 \mathrm{~s}$, it gradually increased from $14 \mathrm{~m} / \mathrm{s}$ to $18 \mathrm{~m} / \mathrm{s}$. Compare the traditional PID controller and fuzzy adaptive PID pitch control strategy with the new compound pitch controller combining fuzzy feed-forward controller with fuzzy adaptive PID controller which is proposed in this paper. The simulation results of pitch angle changing and the value of output power are shown in Fig. (11) and Fig. (12). According to the Fig. (11), after the system experienced the initial state and reached the rated power(when the time is 15s), the current output value of feedforward pitch angle of fuzzy feed-forward controller is about $4^{\circ}$, that can ensure the wind turbine response rapidly to reach the steady rated power. However, fuzzy adaptive PID controller adjusted the PID parameters based on the feedforward pitch angle. The output power's overshoot of wind turbine reduced by $3 \%$ due to the pitch control system which is combination of the two, and settling time shortened correspondingly. When the wind speed increased to the vicinity of $18 \mathrm{~m} / \mathrm{s}$, the output value of feed-forward pitch angle of fuzzy feed-forward controller was about $2^{\circ}$, and the rapid response 


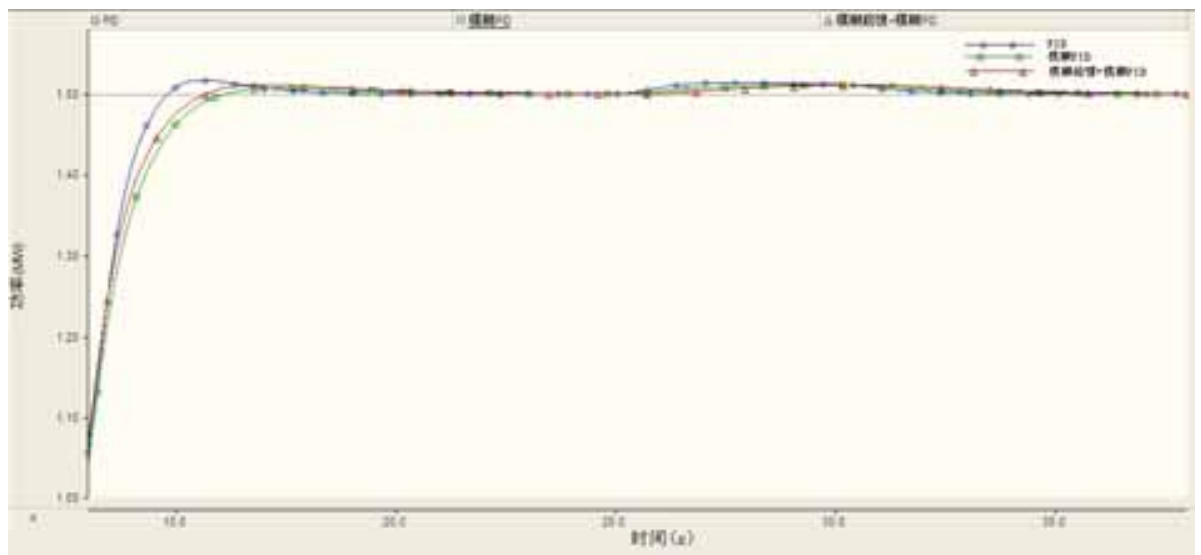

Fig. (12). Power response near the rated wind speed.

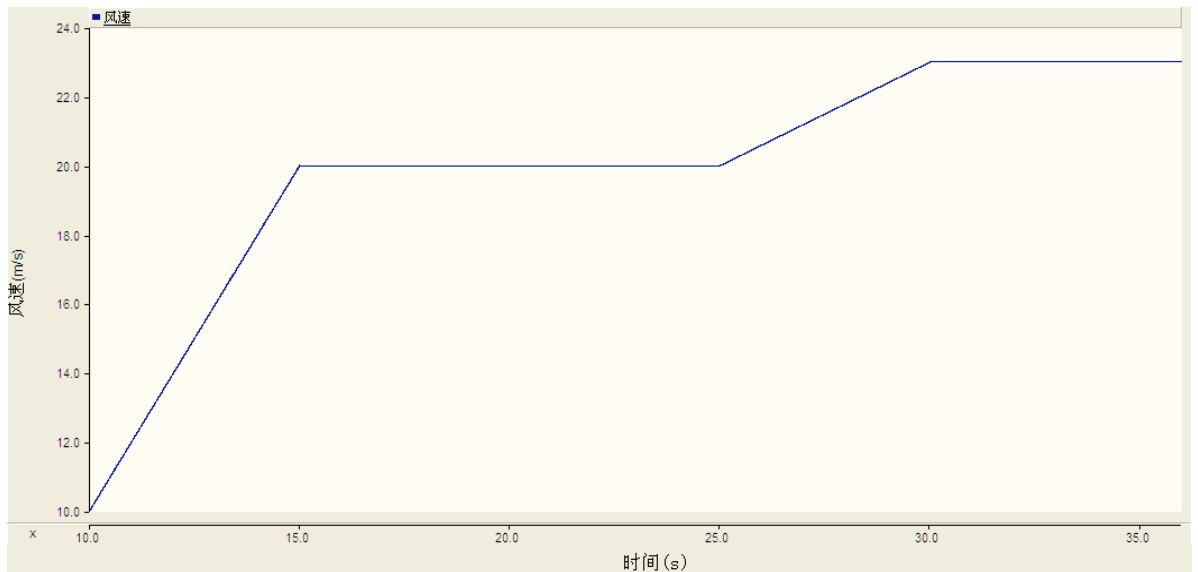

Fig. (13). Wind speed profile.

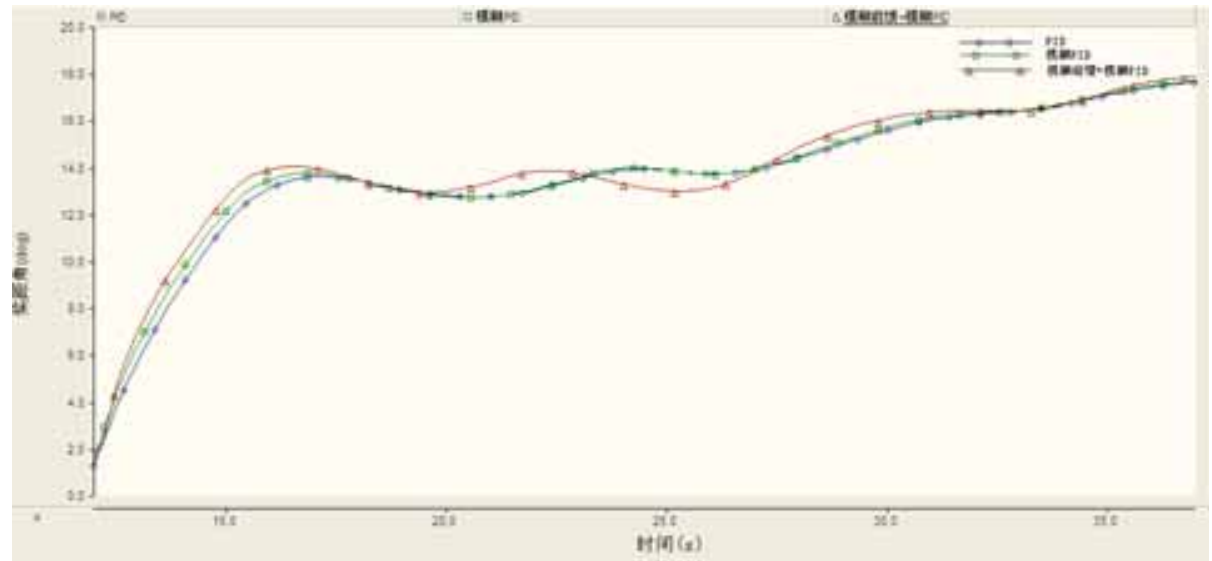

Fig. (14). Pitch response near the cutout wind speed.

of wind turbine maintain the rated power at the vicinity of $1.5 \mathrm{MW}$.

(2) In the vicinity of cut-out wind speed. According to the Fig. (13), from $10 \mathrm{~s}$ to $15 \mathrm{~s}$, wind speed gradually increased from $10 \mathrm{~m} / \mathrm{s}$ to $20 \mathrm{~m} / \mathrm{s}$; from $25 \mathrm{~s}$ to $30 \mathrm{~s}$, it gradually increased from $20 \mathrm{~m} / \mathrm{s}$ to $23 \mathrm{~m} / \mathrm{s}$. The simulation results of pitch angle changing and the value of output power are shown in Fig. (14) and Fig. (15). According to the Fig. (14), the output value of pitch angle of fuzzy feed-forward controller is about $1.5^{\circ}$ at $20 \mathrm{~s}$; the output value of feed-forward controller is about $1^{\circ}$ in the vicinity of $32 \mathrm{~s}$. Based on the research above, the new compound controller designed in this paper has faster response equally to ensure the better control effect of wind turbine. 


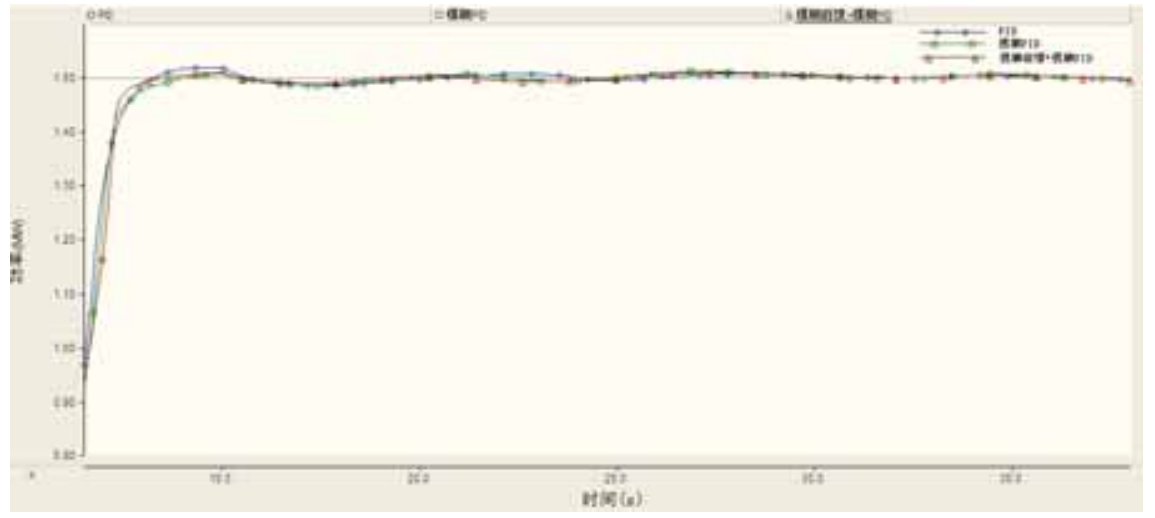

Fig. (15). Power response near the cutout wind speed.

\section{CONCLUSION}

Due to the complexity structure of wind turbine and the strongly nonlinear of the wind speed in wind farm, single PID pitch controller can not achieve satisfactory results when the speed is above the rated wind speed. The fuzzy feed-forward control was introduced into the pitch control system in this paper, based on fuzzy adaptive PID control, a new compound controller combining fuzzy feed-forward control with fuzzy adaptive PID control was designed. Fuzzy feed-forward controller can provide different reasonable feed-forward pitch angles in the vicinity of rated wind speed and cut-out wind speed based on the actual operation aerodynamic characteristics of wind turbine to achieve the goal of rapid compensation. And the fuzzy adaptive PID controller can solve the problem that it is difficult to adjust the parameters of PID controller. The simulation results of $1.5 \mathrm{MW}$ wind turbine show that the new compound pitch controller satisfied the control requirement of wind turbine, reduced the overshoot of output power, shortened the settling time and gained a more satisfying effect.

\section{CONFLICT OF INTEREST}

The authors confirm that this article content has no conflict of interest.

\section{ACKONWLEDGEMENTS}

This work is supported by the Fundamental Research Funds for the Central Universities (2013JBM078).

\section{REFERENCES}

[1] Z. Xin-fang, X. Da-ping, L. Yue-gang, and L. Yi-bing, "Adaptive fuzzy control for large-scale variable speed wind turbines," Journal of System Simulation, vol. 16, no. 3, pp. 573-577, 2004.
[2] X. Ling-feng, X. Da-ping, G. Feng, and L. Yue-gang, "Compound pitch-control of wind turbine generator based on neural network," Journal of North China Electric Power University, vol. 36, no. 1, pp. 28-34, 2009.

[3] G. Peng, "Variable pitch control of wind turbine generator combined with fuzzy feed forward and fuzzy PID controller," In: Proceedings of the CSEE, 2010, pp. 123-128.

[4] S. Guo-xia, L. Xiao-cong, and C. Yi-ming, "Modeling and simulation of variable-speed wind generator system with large capacity," Electric Power Automation Equipment, vol. 27, no. 10, pp. 69-72, 2007.

[5] M. Yin, G. Li, M. Zhou, and C. Zhao, "Modeling of the wind turbine with a permanent magnet synchronous generator for integration," IEEE, Power Engineering Society General Meeting, Tampa, FL, USA: pp. 1-6, 2007.

[6] D. Zhen-lan, C. Meng-zeng, C. Xu, and L. Zhi-bin, "Research on Variable pitch control system for large-scale wind turbine," Electric Machines and Control Application, vol. 38, no. 3, pp. 38-44, 2011.

[7] Y. Hang-ye, Control Technology of Wind Turbine Generator. Beijing: China Machine Press, 2002.

[8] G. Feng, "Modeling of wind turbine and research on pitch control," $\mathrm{PhD}$. thesis, North China Electric Power University School of Control and Engineering, Beijing, China, 2008.

[9] T. Senjyu, R. Sakamoto, and N. Urasaki, "Output power leveling of wind turbine generator for all operating regions by pitch angle control," IEEE Transactions on Energy Conversion, vol. 21, no. 2, pp. 467-475, 2006.

[10] L. Yonggang, L. Wei, C. Baoling, and L. Hongwei, "Study on electro hydraulic propotion and pitch-controlled technology of wind turbine," Acta Energiae Solaris Sinica, vol. 28, no. 6, pp. 658-662, 2007.

[11] L. Guo-yong, Intelligent Control and the Implementation in MATLAB. Beijing: Publishing House of Electronics Industry, 2005.

[12] G. Feng, X. Da-ping, and L. Yue-gang, "Feed forward fuzzy-pi pitch-control for large-scale wind turbines," Chinese Journal of Power Engineering, vol. 28, no. 4, pp. 537-542, 2008.

[13] W. Bin, W. Yan, D. Hong, Y. Weimin, and Y. Huawu, "Variablepitch control of wind turbine at high wind speed," Electric Power Automation Equipment, vol. 30, no. 8, pp. 80-83, 2010.

Received: November 20, 2014

(C) Xiao et al.; Licensee Bentham Open.

This is an open access article licensed under the terms of the Creative Commons Attribution Non-Commercial License (http://creativecommons.org/licenses/by-nc/3.0/) which permits unrestricted, non-commercial use, distribution and reproduction in any medium, provided the work is properly cited. 